\title{
Efficient use of microwave EMF and multilevel high temperature sterilization modes in apple puree technology for dietetic nutrition
}

\author{
M.M. Rakhmanova ${ }^{2}$, A.F. Demirova ${ }^{1,3}$, M.E. Akhmedov ${ }^{1,3^{*}}$, Z.A. Abdulkhalikov ${ }^{1}$, and T.N. \\ Daudova $^{1}$ \\ ${ }^{1}$ Daghestan State Technical University, 367015 Makhachkala, Russia \\ ${ }^{2}$ Technical College, 367013 Makhachkala, Russia \\ ${ }^{3}$ Dagestan State University of National Economy, 367008 Makhachkala, Russia
}

\begin{abstract}
The article is dedicated to improving the quality of apple puree with xylitol for dietetic nutrition due to the development and implementation of a new technological process. This is microwave boiling of apples, rather than traditional steaming using saturated steam before chopping, with the development of a device for its implementation and multilevel hightemperature sterilization modes with prebake of apple puree in glass jars in microwave EMF. The analysis of research and technical data proved that pre-heat treatment of apples with saturated steam and traditional sterilization modes have a considerable duration, which impairs the finished products quality and has an adverse effect on the nutrient composition of the raw material during processing. Substituting the traditional method of pre-heat treatment of apples for their short-time processing in microwave EMF reduces the process by more than twice, which, in turn, contributes to an increased preservation of the nutrient composition of apples, while enhancing the yield of apple puree. For the implementation of microwave processing method of raw materials, a new design of the device for electromagnetic treatment of plant roughage has been developed, providing a uniform and more intensive heat treatment of raw materials in a continuous flow. Rapid multilevel high-temperature sterilization modes with the application of apple puree in glass jars in microwave EMF, liquid hightemperature heat devices and an autoclave basket, providing the opportunity for thermal sterilization of the product without creating reverse pressure in the machine, generally contribute to reducing heat costs and increasing the nutritional value.
\end{abstract}

\section{Introduction}

Canned food for dietetic nutrition needs to have a high nutritional value and some technologies for their production envisage additional introduction of certain nutrients required for functional nutrition into the food product $[1,2,3,4]$. Nevertheless, it is a significant practical task to find manufacturing technologies that guarantee maximum

\footnotetext{
${ }^{*}$ Corresponding author: akhmag49@mail.ru
} 
preservation of the nutrient composition of the raw material and thereby provide a high nutritional value of the finished product.

Analysis of literature sources and traditional technologies for the manufacture of canned products displays $[5,6]$ that among the most important processes that significantly impact the quality of the finished product are the processes of pre-heat treatment of raw materials especially cooking as well as the final heat treatment of half - finished products like sterilization $[7,8,9,10,11,12]$.

Considering that imperfection of heat exchange processes is the origin causing a reduction in the nutritional value of finished products, we have considered the relevance of improving the processes of boiling and sterilization, using partial technological modes with the application of microwave EMF and high-temperature heat devices. This will guarantee a soft processing of raw materials, with a more comprehensive preservation of food and biological value.

Study objective is to upgrade the production technology of apple puree with xylitol for dietetic nutrition by intensifying the process of fruit boiling before wiping and developing new, multilevel high-temperature sterilization modes using microwave EMF and liquid hightemperature heat devices.

\section{Methods of the study}

Microwave processing of apples and preheating of the half-finished product in glass jars before sterilization was performed in a microwave oven MN 654S. New sterilization modes were installed on a laboratory measuring complex on the basis of measuring the dynamic changes in the temperature of the product in a glass jar. The temperature in the relevant areas of the product can was performed using chromel-copel thermocouple attached to an electromotive force recorder KSP-4.

\section{Research result}

On the basis of the identified disadvantages of the traditional technological cycle of apple puree production with xylitol for dietetic nutrition, we have determined the practicability of introducing a new technological process. It is microwave boiling of apples, instead of traditional steaming by saturated steam before chopping with the development of a device for its implementation and speed-up sterilization modes with preheating of puree in glass jars in microwave EMF [7,8,10,12,13,14,15].

Prepared apples are treated with microwave in a device for processing plant raw materials in an ultra-high frequency electromagnetic field (microwave EMF) of $2400 \pm 50 \mathrm{MHz}$ and a power of 280-700 W[16], where they are processed for 2.0-3.5 minutes, followed by chopping.

Comparative data on the output and quality of puree are given in table 1 .

Table 1. Output and quality indices of apple puree during traditional processing and exposure to microwave EMF

\begin{tabular}{|l|c|c|c|c|c|c|}
\hline $\begin{array}{l}\text { Treatment } \\
\text { method }\end{array}$ & $\begin{array}{c}\text { Variety of } \\
\text { apples }\end{array}$ & $\begin{array}{c}\text { Power of } \\
\text { the } \\
\text { microwave } \\
\text { field, W }\end{array}$ & $\begin{array}{c}\text { Treatme } \\
\text { nt time, } \\
\text { min }\end{array}$ & $\begin{array}{c}\text { Fruit } \\
\text { temperature, }\end{array}$ & $\begin{array}{c}\text { Puree } \\
\text { output, } \\
\%\end{array}$ & $\begin{array}{c}\text { Vitamin } \\
\text { content, } \\
\mathrm{mg} / 100 \\
\mathrm{~g}\end{array}$ \\
\hline & Florina & 280 & 3,5 & $89-90$ & $73-74$ & 8,2 \\
\hline
\end{tabular}




\begin{tabular}{|c|c|c|c|c|c|c|}
\hline $\begin{array}{c}\text { Microwave } \\
\text { EMF } \\
\text { treatment }\end{array}$ & 420 & 2,5 & $91-92$ & $76-77$ & 9,1 \\
\cline { 3 - 7 } & 700 & 2,0 & $92-93$ & $79-80$ & 9,3 \\
\cline { 3 - 6 } $\begin{array}{c}\text { Saturated } \\
\text { steam } \\
\text { treatment }\end{array}$ & - & 20 & $61-64$ & $67-69$ & 6,5 \\
\cline { 2 - 6 } & & & & & \\
\hline
\end{tabular}

The influence of the application of microwave cooking of whole apples is evident. According to the analysis of experimental findings, while using microwave EMF instead of the traditional method, due to increased cell permeability under its influence, the output of puree increases by $10-12 \%$ and the puree has high organoleptic indicators. The content of vitamin $\mathrm{C}$ is $50 \%$ higher than that received by traditional technology.

For the implementation of this process, we have designed a device for processing plant raw materials in microwave EMF (Fig.1) [9]. Its application will guarantee a high output of the finished product, complete prevention of oxidative processes occurring with traditional technology, and improvement of finished product quality.

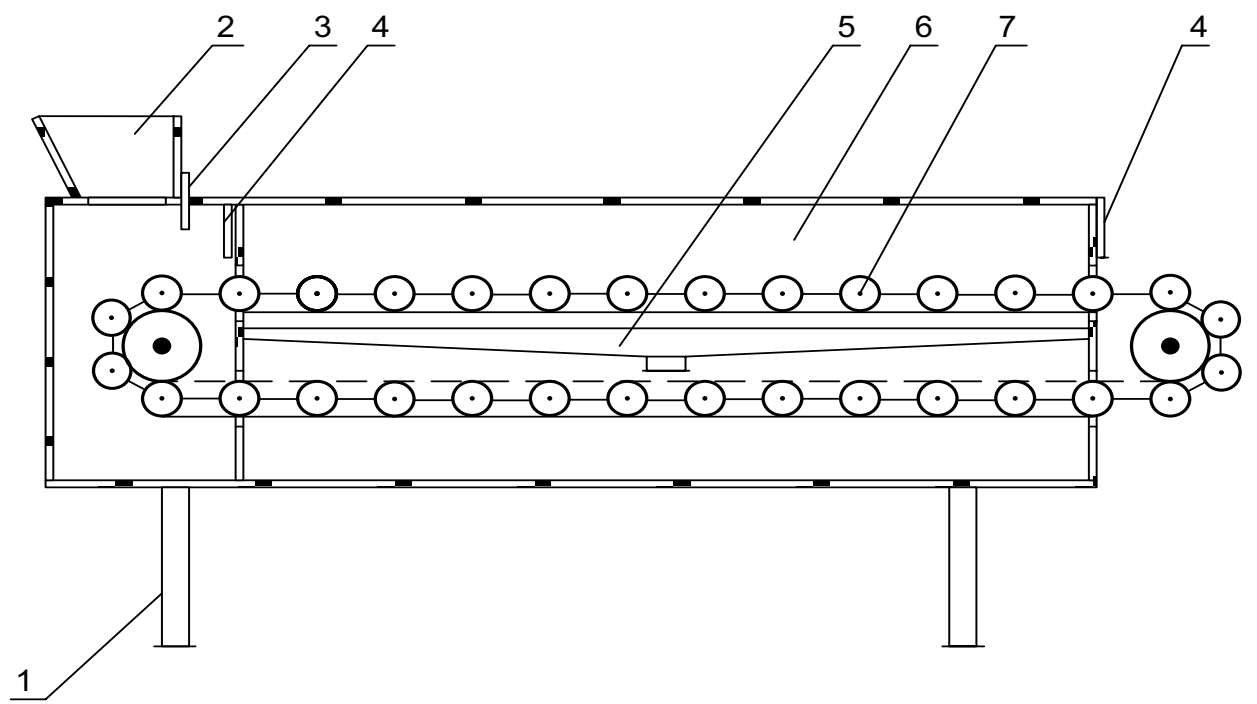

Fig. 1. A device for microwave boiling of raw materials: 1 -a bed; 2 -a charge chute; 3 -a mechanism for controlling the thickness of raw materials' layer; 4-rubber protection shield; 5-a receiver for free-run juice; 6-a microwave chamber; 7 - a conveyor

The device operates in the following way.

Raw material is supplied to a roller conveyor. In this case, the thickness of the raw material layer is adjusted by a damper installed above the conveyor. Then the raw material gets into the microwave chamber, where it is exposed to microwave EMF for 2.5-3.5 minutes. After leaving the microwave chamber, the raw material is delivered to the pulpifier for chopping.

The most significant stage in the technological cycle of canned food production is sterilization. For a comprehensive evaluation of this process, we investigated the process of thermal sterilization according to the traditional regime. $\frac{25-20-25}{100} 118 \mathrm{kPa}[2](f i g .2)$ 


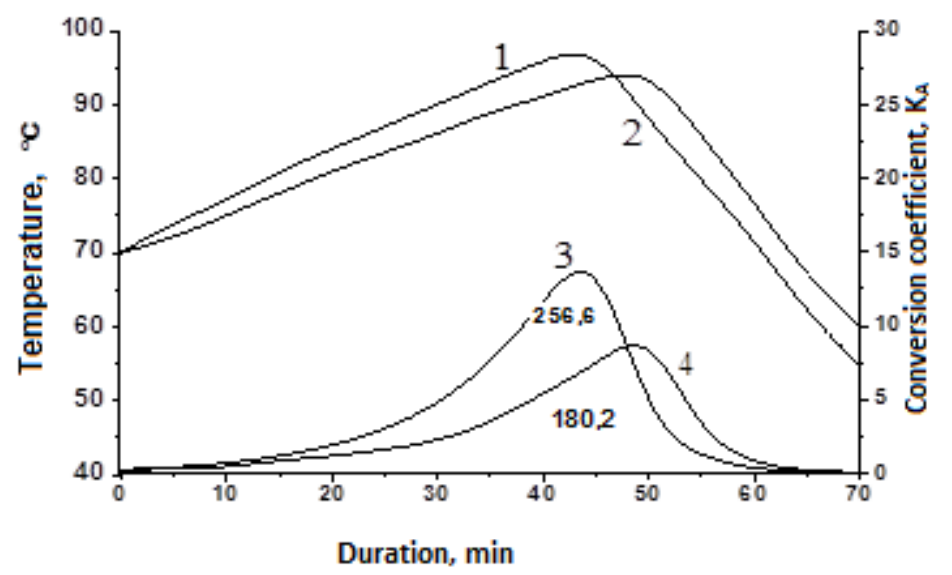

Fig. 2. Curves of temperature development $(1,2)$ and microbial death $(3,4)$ in the wall $(1,3)$ and central $(2,4)$ spaces of apple puree for dietetic nutrition in 0.5 -liter glass jars over heat treatment in the traditional mode

analysis of the graphic material indicates that the mode ensures the necessary level of industrial safety, since the values of the levels of sterilizing effect meet the required values. The degree of industrial sterility of heat treatment is respectively: $256,6,4 /(150-200)=1,3$ and $180,2 /(150-200)=1,0$, which prove the reliability of the product. Nevertheless, there is a considerable difference in their values for the central and wall spaces. Moreover, the mode has a long, equal to 70 minutes, duration of heat treatment.

For the determination of rapid sterilization modes $[15,16]$, it is suggested to use microwave heating of puree in glass jars up to $90-920 \mathrm{C}$ before capping them for $1.5 \mathrm{~min}$. For the determination of rapid sterilization modes $[15,16]$, it is suggested to use microwave heating of puree in glass jars up to $90-920 \mathrm{C}$ before capping them for $1.5 \mathrm{~min}$.

The dynamics of temperature and microflora death of apple puree with xylitol in a glass jar with a capacity of 0.5 liters under a high-temperature multilevel sterilization mode $\left(\frac{10}{105^{0} \mathrm{C}} \cdot\right)$ - $\left(\frac{8}{80^{0} \mathrm{C}} \cdot \frac{8}{60^{\circ} \mathrm{C}} \cdot \frac{8}{40^{\circ} \mathrm{C}}\right)$ using an autoclave basket and mechanically ensuring that the lids do not break from the glass jars [18] are shown in figure 3. 


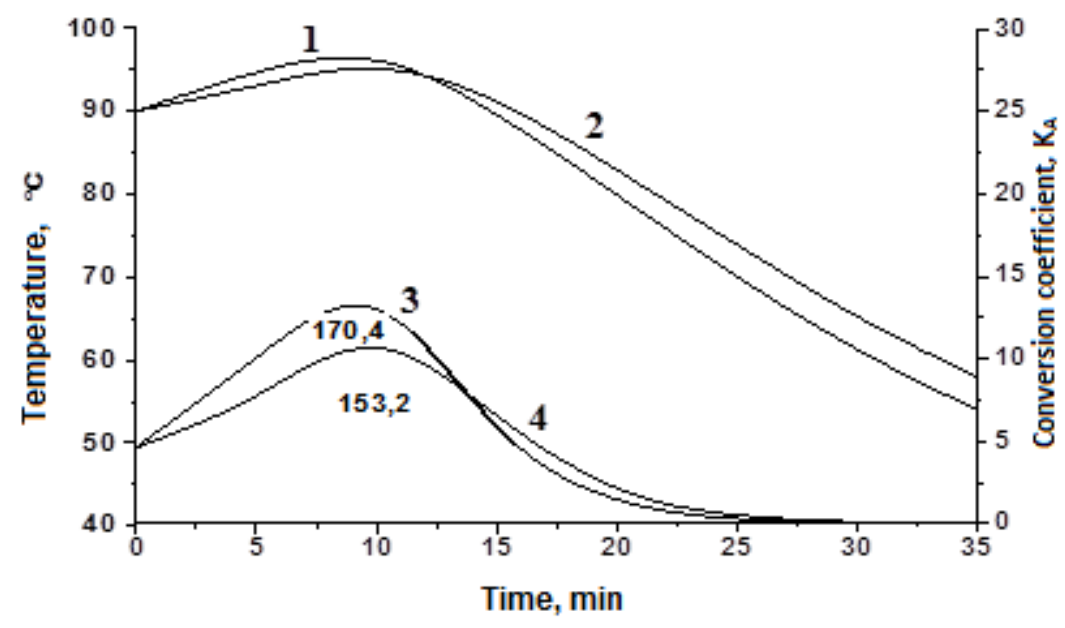

Fig. 3. dynamics of temperature $(1,2)$ and mortality $(3,4)$ in the wall $(1,3)$ and central $(2,4)$ spaces of apple puree with xylitol in a glass jar with a capacity of 0.5 liters during heat treatment under the new sterilization mode.

The duration of the new multilevel high-temperature sterilization mode is decreased by 35 minutes compared to the traditional mode.

Evaluation of the achieved effect of the sterilizing influence indicates that the developed mode of multilevel high-temperature heat treatment ensures the required level of industrial sterility, including relative uniformity of the temperature regime in the wall and middle spaces, which may be explained by the high initial temperature of the product before heat treatment.

The degree of industrial sterilization of heat treatment defined by the ratio of the value of the achieved sterilizing effect to the required value (150-200 conditional minutes) [2], for the developed mode at the initial temperature level of $900 \mathrm{C}$ is, respectively: for the wall layer of the product $-170.4 /(150-200)=1.0$ and for the product in the central space of the glass jar $153.2 /(150-200)=1.0$, which prove the product safety and uniformity of heat treatment.

On the basis of the performed pilot studies, an improved technology for the production of apple puree for dietetic nutrition has been designed. (Fig. 4).

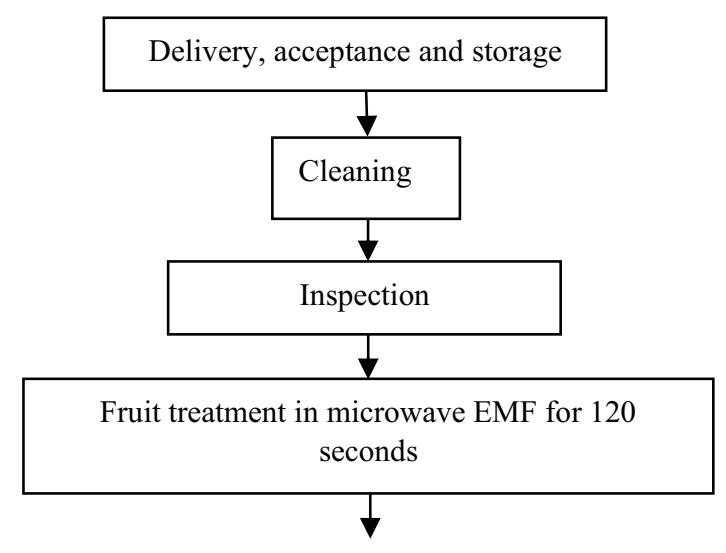




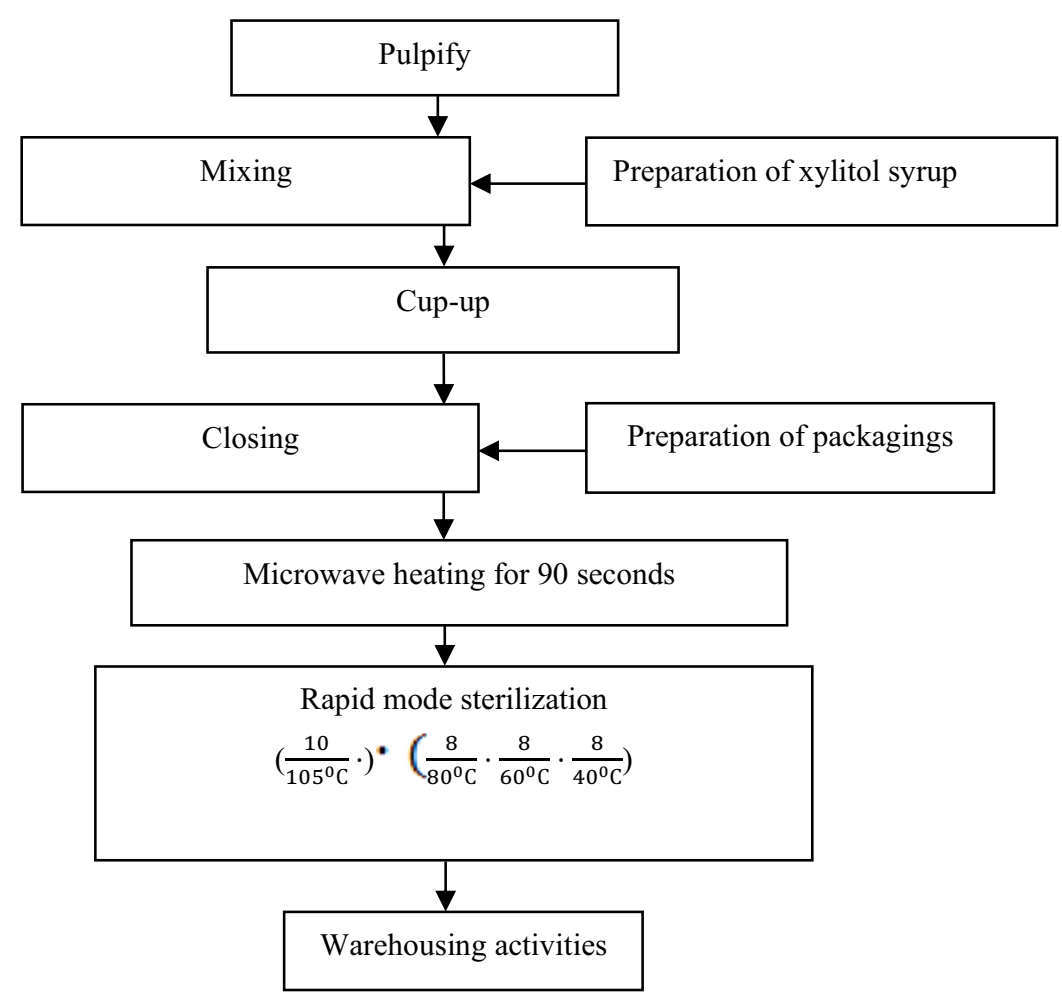

Fig. 4. Block diagram of an improved technology for apple puree production with xylitol using new technical solutions.

For evaluating the impact of new technical solutions on the quality of finished products, the content of vitamin $\mathrm{C}$ in the raw material and apple puree with xylitol made using different technologies was defined (Fig. 5)

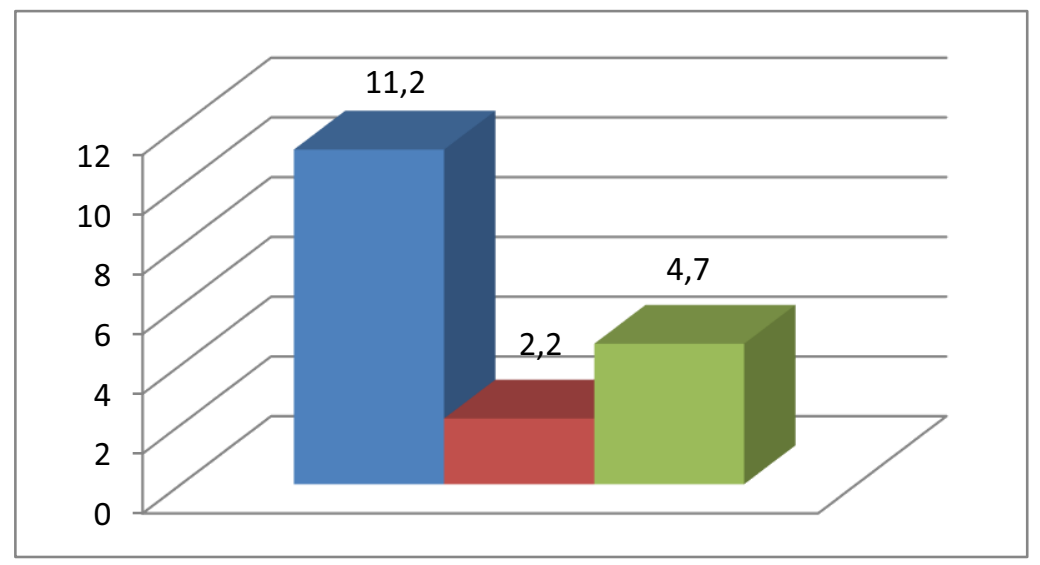

Fig. 5. Vitamin C Content in apples and purees manufactured using different technologies: 1-in apples; 2-using traditional technology; 3-using advanced technology.

The figure demonstrates that using the proposed technical solutions provides the production of apple puree with xylitol with a high nutrient composition. 


\section{Conclusions}

Findings presented in this figure prove the implementation effectiveness of the proposed technical solutions for the use of microwave boiling of apples before wiping and a new sterilization mode. In combination, they reduce the technological cycle of production and increase the nutritional value of the finished product.

\section{References}

1. M.D. Mukailov, N.A. Ulchibekova., T.A. Isrigova, M.E. Akhmedov, U.A. Selimova, International Journal of Advanced Science and Technology (2020)

2. T.A. Isrigova, M.M. Salmanov, M.D. Mukailov, T.N. Ashurbekova, U.A. Selimova, Research Journal of Pharmaceutical, Biological and Chemical Sciences (2016)

3. M. Akhmedov, A. Demirova, V. Piniaskin, R.A. Rakhmanova, New technological and technical solutions in dietary pear compote production, E3S Web of Conferences, 161 (2020)

4. M. Akhmedov, A. Demirova, Z. Abdulkhalikov, T. Daudova, L. Daudova, An enhanced technology of pear compote production through direct bianching with syrup in glass jars and a device for its implementation, E3S Web of Conferences, 161 (2020)

5. B.L. Flaumenbaum, S.S. Tanchev, M.A. Grishin, Basics of food sterilization (Moscow: Agropromizdat, 1986) (in Russian)

6. Technical instructions for the production of canned food, 2, 355 (M.: Pishcheprom, 1977) (in Russian)

7. V.P. Babarin, Sterilization of canned food (Saint Petersburg: GIORD, 2006) (in Russian)

8. C.M.G.C. Renard, J.F. Maingonnat, Thermal processing of fruits and fruit juices, Thermal Food Processing: New Technologies and Quality Issues, (Second Taylor \& Francis, 2012)

9. M.E. Akhmedov, A.F. Demirova, G.D. Dogeev, N.M. Alibekova, R.A. Rakhmanov, Apparatus for treating plant material in an ultrahigh-frequency electromagnetic field. Russian patent for invention No. 2714715 (2020) (in Russian).

10. E.F. Azadova, M.E. Akhmedov, A.F. Demirova, Storage and Processing of Farm Products, 5, 55-57 (2015) (in Russian).

11. M.E. Akhmedov, Food Technology, 1, 15-16 (2008) (in Russian).

12. G.I. Kasyanov, A.F. Demirova, M.E. Akhmedov, Doklady Rossiyskoy akademii sel'skokhozyaystvennykh nauk, 6, 57-59 (2014) (in Russian).

13. T.A. Ismailov, M.E. Akhmedov, A.F. Demirova, E.F. Azadova, Z.M. Gapparova, Method of carrot puree production, Russian patent No. 2651300 A 23 L 3/04. 2017113803, Declared on April 20, 2017 (2018) (in Russian)

14. G.I. Kas'yanov, Food Technology, 1, 35-38 (2014) (in Russian)

15. O.R. Panina, G.I. Kas'yanov, S.V. Rokhman', Food Technology, 1, 122-124 (2014) (in Russian)

16. A.F. Demirova, M.E. Akhmedov, Storage and Processing of Farm Products, 1, 22-24 (2011) (in Russian).

17. M.E. Akhmedov, A.F. Demirova, G.D. Dogeyev, E.F. Azadova, R.A. Rakhmanova, Apparatus for treating plant material in an ultrahigh-frequency electromagnetic field, Patent of the Russian Federation No. 2714715. IPC A23L1 / 00 No. 2019109774. (2020) (in Russian) 
18. M.E. Akhmedov, A.F. Demirova, G.D. Dogeyev, M.M. Alibekova, R.A. Rakhmanova, Autoclave basket. Russian patent for utility model No.183292 (2018) (in Russian).

19. M.E. Akhmedov, Z.A. Demirova, T.N. Abdulkhalikov, L.A. Daudova, Improved technology for the production of compote from pears utilizing blanching of fruits in jars with sugar syrup and devices for its implementation, E3S Web of Conferences, 161 (2020) 